\title{
DEPRESSÃO NA ADOLESCÊNCIA E SUAS CONSEQUÊNCIAS
}

\author{
Maria Magali Viegas de Souza ${ }^{1}$ \\ Marcos Antônio Viegas Filho ${ }^{2}$
}

Resumo: Conhecida como o mal do século, a depressão se tornou uma epidemia social. A síndrome pode ocorre em qualquer faixa etária, gênero ou condições socioeconômicas, entre os adolescentes é ainda é um problema pouco reconhecido, resultando muitas vezes no desenvolvimento comportamentos de automutilação chegando até o suicídio. Vários fatores podem contribuir para evolução da síndrome, devido a adolescência ser uma época das descobertas e busca da tal afirmação social, para isso, é preciso investigar o que causa real impacto nos jovens.

Palavras-chaves: Depressão - Adolescência - Suicídio.

Abstract: Known as the evil of the century, depression has become a social epidemic. The syndrome can occur in any age group, gender or socioeconomic conditions, among adolescents it is still a problem little recognized, often resulting in the development of self-mutilation behaviors leading up to suicide. Several factors can contribute to the evolution of the syndrome, due to the fact that adolescence is a time of discovery and the search for the longed social affirmation, therefore, it is necessary to investigate what causes real impact on young people.

Keywords: Depression. Adolescence. Suicide.

Conhecida como a doença do século, a depressão atinge por volta de 350 milhões de pessoas em todo mundo, segundo os últimos dados da OMS - Organização Mundial de Saúde de 2019. No Brasil a doença atinge 5,8\% da população, bem como distúrbios associados a ansiedade que afetam 9,3\%.

Ainda de acordo com a OMS, a depressão é a doença que mais contribui com a incapacidade psico-físico-social no mundo, cerca de 7,5\%, também considerada a principal causa de mortes por suicídios, com cerca de 800 mil casos por ano.

Diferentes das outras patologias, a doença-depressão não apresenta nenhum sintoma físico, ou seja, não aparece em nenhum exame de hemograma ou tomografia, e dependendo da pessoa pode ser manifestada de várias formas. É uma doença que pode atingir qualquer faixa etária, na adolescência, se torna mais complicado de ser diagnosticado devido a ser uma fase de muita transição, e por ser uma doença silenciosa 
ela pode evoluir e levar a alguns fatores comportamentais como a automutilação, e em casos mais grave, o suicídio.

Estudos comprovam que os adolescentes gastam muito tempo na internet, pois nesse mundo virtual eles encontram um espaço de expressões e descobertas, o que acabam deixando-os mais expostos, assim sendo classificados nas pesquisas como grupo de risco, pois tais exageros no uso das tecnologias podem gerar comportamentos para uma conduta suicida, e que o mau uso das tecnologias podem trazer prejuízos à saúde mental de crianças e adolescentes. (KIEFER, 2014)

Ainda vivemos numa época das desigualdades sociais, época marcada pela revolução tecnológica e enfraquecimento das redes sociais, solidão e crises de identidade. Podendo gerar nas crianças e adolescentes sentimentos de passividade e dependência.

Desta forma, a família tem um papel fundamental no desenvolvimento da resiliência, o que reforça a capacidade individual para encarar determinadas situações de risco, e que a mesma funciona como mecanismo de defesa.

Segundo a OMS A adolescência é definida como um período biopsicossocial, segunda fase da vida que vai dos 10 aos 20 anos. Critério adotado também pelo Ministério da Saúde do Brasil e pelo Instituto Brasileiro de Geografia e Estatística IBGE (BRASIL, 2007).

Para Formigli, Costa \& Porto (2000) a adolescência inicia-se com as mudanças corporais da puberdade e termina com a inserção social, profissional e econômica na sociedade adulta. Cientificamente a adolescência começa na fase púbere, aproximadamente dos 12 aos 20 anos de idade. Apesar de não ter uma idade definida, considera-se que ocorre um processo de maturidade sexual ou fertilidade. (PAPALIA E OLDS 2000)

No Brasil, o ECA - Estatuto da Criança e do adolescente, define adolescente na faixa etária dos 12 aos 18 anos de idade (ECA - Lei 8.069, de 13 de julho de 1990).

Lidz (1983) e Serra (1997) argumentam existir várias adolescências, que vão de acordo com as características de cada indivíduo e de seu contexto social e histórico. Tantas formas e histórias, a fase juvenil é única, os jovens buscam autenticidade e sentido para si mesmo. É uma fase considerada com muita complexidade, fase de mudanças físicas e psicológicas, e por este motivo pode ser considerado o período mais forte e intenso da vida. Para Papalia e Olds (2000, p. 315) "um dos grandes paradoxos 
da adolescência é o conflito entre o anseio do jovem de afirmar uma identidade única e um desejo irresistível de ser exatamente como seus amigos ou amigas".

$\mathrm{Na}$ adolescência, a aparência dos jovens muda em função das alterações hormonais da puberdade. Seu pensamento muda à medida que desenvolvem a capacidade de lidar com abstrações. Seus sentimentos mudam sobre quase tudo. Todas as áreas de desenvolvimento convergem quando os adolescentes confrontam sua principal tarefa, a de estabelecer uma identidade adulta - incluindo uma identidade sexual - que irá se estender-se até a idade adulta.

Bem, seja qual for a nomenclatura vale salientar que cada vez a infância está mais curta, e que os efeitos dessa maturação podem gerar efeitos negativos. "[...] A maturação precoce está associada com a tendência para comportamento arriscado". (PAPALIA \& OLDS, 2000, p. 316).

Durante muito tempo a depressão em adolescentes eram descartadas, devido a crenças de que os jovens não tinham maturidade mental para desenvolver a doença. Em 1971, Freud defendia que os deprimidos apresentavam sintomas de "redução do sentimento de autoestima" e expectativas ilusórias de punição", sentimento de culpa por suas escolhas, assim concluía que esses indivíduos não podiam ficar deprimidas. Pesquisas realizadas por Fleitlich-Bilyk e Goodman no Brasil, apontam que $1 \%$ dos jovens entre sete e catorze anos apresentam algum transtorno depressivo, e que os mesmos estudos evidenciaram um maior número de jovens em escolas públicas. (SILVA, 2016)

O diagnóstico nos adolescentes se torna mais difícil, devida a fase de crescimento ou fatores hormonais, teorias também apontam que nesta fase as meninas tendem a ter o dobro de chances de desenvolver a depressão do que os meninos.

Dentre vários comportamentos de risco a automutilação é o mais comum entre os adolescentes, e que vem chamando a atenção de pais e profissionais da educação e da saúde. A prática de utilizar o corpo para ferir-se, modificar e/ou comunicar-se pode ser vista em várias culturas, desde as primitivas às contemporâneas, a automutilação não é um hábito novo. (ARAÚJO e Col. 2016)

A prática de ferir-se ou modificar o próprio corpo acompanha a história da humanidade. Em épocas, Debates contemporâneos sobre Educação para a Sexualidade 235 religiões e culturas distintas, foram produzidos variados sentidos e intervenções sociais sobre a mesma. Assim, a prática de provocar uma lesão ou ferimento no próprio corpo, hoje definida como automutilação, é uma produção histórica e cultural. O que aconteceu é que essa prática tem sido atualizada a partir de 
outros sentidos, termos e intencionalidades. (GONÇALVES E SILVA, 2017, p. 235)

Neste sentido, ao se deparar com assuntos relacionados ao corpo pode-se entender de várias formas, manifestações, sentimento de pertença para alguns grupos ou até mesmo um pedido de ajuda.

Portanto percebe-se que as pessoas que se cortam sentem uma sensação de prazer e não de dor, pois a endorfina é considerada um analgésico natural que gera prazer e bem estar. Na maioria dos casos, está relacionada a vários problemas psicológicos, como depressão, ansiedade, transtorno obsessivo compulsivo (TOC) e transtornos alimentares.

Fato que a automutilação não é reconhecida como um ato saudável no Brasil, reconhecer que se trata de um distúrbio e começar um tratamento é o primeiro passo.

Para uma possível cura ou tratamento, é importante um trabalho de escuta com intervenções, isso se dá de acordo com o tempo de cada indivíduo. Mas Ainda o melhor remédio é a informação e a prevenção.

Deste modo, a família tem um papel fundamental no resgate e no acolhimento do indivíduo depressivo. Ficar atento aos sinais, "Isolamento, marcas de automutilação ou práticas de atividades arriscadas, todos com repetição, são considerados sintomas de que aquele adolescente precisa de ajuda". (OLIVEIRA, 2018)

Para concluir, o jovem busca na qualidade de vida a sua auto realização, e através dela, ele pode deixar de ser um prisioneiro do futuro e viver o hoje.

Compreender tais vicissitudes e conhecer seus direitos é dever da sociedade, desta forma minimizar o impacto deste fenômeno, através de debates, atitudes e cobranças de políticas concretas.

1- Psicóloga e Professora Universitária. Especialista em Gestão do Capital Humano, Mestre e Doutora em Saúda Pública.

2- Jurista, Administrador e Professor do IFPE. Especialista em Educação, Mestre e Doutor em Saúde Pública. 


\section{REFERÊNCIAS}

7 Organização Mundial de Saúde (OMS). Relatório sobre saúde no mundo 2001. Saúde mental: nova concepção, nova esperança. Genebra: OMS; 2001.

ARAÚJO, Juliana Falcão Barbosa de; CHATELARD, Daniela Scheinkman; CARVALHO, Isalena Santos; VIANA, Terezinha de Camargo. O corpo na dor: automutilação, masoquismo e pulsão. Estilos clin. vol.21 no.2 São Paulo ago. 2016http://dx.doi.org/http//dx.doi.org/0.11606/issn.1981-1624.v21i2p497515. DOI: http//dx.doi.org/0.11606/issn.1981-1624.v21i2p497-51

FORMIGLI, V. L. A., COSTA, M. C. O., \& Porto, L. A. (2000). Evaluation of a comprehensive adolescent health care service. Cadernos de Saúde Pública, 16, 831-841. FORMIGLI, V. L. A., COSTA, M. C. O., \& Porto, L. A. (2000). Evaluation of a comprehensive adolescent health care service. Cadernos de Saúde Pública, 16, 831-841. FREUD, Sigmund. [1914-1916] Luto e Melancolia. Obras Completas Vol. 12, Trad. Paulo César de Souza. São Paulo: Companhia das Letras, 2010.

FREUD, Sigmund. [1914-1916] Luto e Melancolia. Obras Completas Vol. 12, Trad. Paulo César de Souza. São Paulo: Companhia das Letras, 2010.

GONÇALVES, Jaqueline Nascimento; SILVA, Elenita Pinheiro de Queiroz. Automutilação, gênero, sexualidade e escola: debates contemporâneos sobre Educação para a sexualidade / [organizadoras] Paula Regina Costa Ribeiro, Joanalira Corpes Magalhães - Rio Grande: Ed. da FURG, 2017. 284 p. ISBN: 978-85-7566-461-2 1 .

KEIFER, Sandra. Exagero de tecnologia deixa crianças e adolescentes desconectados do mundo real. Disponível em: https://www.em.com.br/app/noticia/gerais/2014/05/25/interna_gerais,532336/exagerode-tecnologia-deixa-criancas-e-adolescentes-desconectados-do-mundo-real.shtml. Acesso 28 ago. 2019.

LIDZ, T. A pessoa: seu desenvolvimento durante o ciclo vital. Porto Alegre: Artes Médicas, 1983.

OLIVEIRA, Cassia. O que está levando uma geração de jovens à depressão?

OLIVETO, Paloma. Uso excessivo da Internet Aumenta Riscos de Adolescentes desenvolverem DTAH. 2018. Disponível em: https://www.correiobraziliense.com.br/app/noticia/ciencia-esaude/2018/07/18/interna_ciencia_saude,695615/excesso-de-internet-leva-aodesenvolvimento-de-hiperatividade.shtml- postado em 18/07/2018 06:00. Acesso 28 out. 2019.

Organização Mundial de Saúde (2008) Classifi Estatística Internacional de Doenças e Problemas Relacionados à Saúde - CID-10. 
PAPALIA, Diane E. OLDS, Sally Wendkos. Desenvolvimento Humano. $7^{\text {a }}$ edição Porto Alegre: Artes Médicas Sul, 2000.

PAULA, Marcos Ferreira de. Pode o conhecimento dar alguma alegria? Uma interpretação da "Melancolia I ", de Albrecht Dürer, a partir da "Ética" de Spinoza. Kriterion: Revista de Filosofia. Kriterion vol.55 no.130 Belo Horizonte Dec. 2014.

SERRA, E. Adolescência: perspectiva evolutiva. Em Anais do VII Congresso INFAD (pp. 24-28). Oviedo (Espanha), 1997. 